\title{
CIE L*a*b*: comparison of digital images obtained photographically by manual and automatic modes
}

\section{Fabiana Takatsui(a) Marcelo Ferrarezi de Andrade(a) Maximiliano Piero Neisser ${ }^{(b)}$ Luiz Antônio Borelli Barros(c) Leonor de Castro Monteiro Loffredo ${ }^{(c)}$}

\footnotetext{
(a) Department of Restorative Dentistry, Araraquara Dental School, Universidade Paulista "Júlio de Mesquita Filho" - UNESP, Araraquara, SP, Brazil.

(b) Department of Clinical Research in Periodontology, Universidade de Taubaté UNITAU, Taubaté, SP, Brazil.

(c) Department of Social Dentistry, Araraquara Dental School, Universidade Paulista "Júlio de Mesquita Filho" - UNESP, Araraquara, SP, Brazil.
}

\begin{abstract}
The aim of this study was to analyze the color alterations performed by the CIE L*a*b* system in the digital imaging of shade guide tabs, which were obtained photographically according to the automatic and manual modes. This study also sought to examine the observers' agreement in quantifying the coordinates. Four Vita Lumin Vaccum shade guide tabs were used: A3.5, B1, B3 and C4. An EOS Canon digital camera was used to record the digital images of the shade tabs, and the images were processed using Adobe Photoshop software. A total of 80 observations (five replicates of each shade according to two observers in two modes, specifically, automatic and manual) were obtained, leading to color values of $\mathrm{L}^{*}, \mathrm{a}^{*}$ and $\mathrm{b}^{*}$. The color difference $(\Delta \mathrm{E})$ between the modes was calculated and classified as either clinically acceptable or unacceptable. The results indicated that there was agreement between the two observers in obtaining the $\mathrm{L}^{*}, \mathrm{a}^{*}$ and $\mathrm{b}^{*}$ values related to all guides. However, the B1, B3, and $\mathrm{C} 4$ shade tabs had $\Delta \mathrm{E}$ values classified as clinically acceptable $(\Delta \mathrm{E}=0.44, \Delta \mathrm{E}=2.04$ and $\Delta \mathrm{E}=2.69$, respectively). The A3.5 shade tab had a $\Delta \mathrm{E}$ value classified as clinically unacceptable $(\Delta \mathrm{E}$ $=4.17)$, as it presented higher values for luminosity in the automatic mode $\left(\mathrm{L}^{*}=54.0\right)$ than in the manual mode $\left(\mathrm{L}^{*}=50.6\right)$. It was concluded that the B1, B3 and C4 shade tabs can be used at any of the modes in digital camera (manual or automatic), which was a different finding from that observed for the A3.5 shade tab.
\end{abstract}

Descriptors: Tooth; Color Perception; Image Processing, ComputerAssisted.

\section{Introduction}

Aesthetic dentistry relies on the crafting of a restoration that properly integrates with the tooth structure in all aspects, including color. Color perception is a subjective process that involves the contribution of three main factors:

- light (the light source),

- the object (tooth) and

- the observer (dentist).

According to Yap et al., ${ }^{1}$ the lighting of the dental clinic and the dental laboratory can influence color selection in that different lighting sources may present different wavelengths. In this way, fluorescent light can acti- 
vate the blue portion of the spectrum, and incandescent light can activate the yellow-red portion.

The determination of color may be visual or instrumental, though the former is the approach most commonly used by professionals. In a study by Rodrigues et al., ${ }^{2} 60$ dentists were interviewed, and, although they all employed the method of visual color selection with a preference for the Vita shade guide as a standard, $75 \%$ reported experiencing difficulty in this measurement. The subjective nature of visual assessment has also been reported by Mayekar, ${ }^{3}$ Hammad, ${ }^{4}$ and Dagg et al. ${ }^{5}$ Thus, Yap et al. ${ }^{1}$, Dozic et al., ${ }^{6}$ and Mutlu-Sagesen et al. ${ }^{7}$ have recommended the use of digital instruments, including the colorimeter and portable instruments of color and other digital imaging methods, which could help eliminate the subjectivity of visual assessment.

Different scales for the visual determination of color have been developed by Vita Zahnfabrik (Bad Sackingen, Germany), thereby facilitating the understanding of the primary characteristics of tooth color, such as chroma, value and hue, with the Vita Lumim Vacuum, 3D-Master and Vitapan scales, among others.

According to Yamanel et al., ${ }^{8}$ in 1979, a specific commission (Commission International de L'Eclairage), proposed the CIE L*a*b* system, consisting of three coordinates, in which $\mathrm{L}^{*}$ refers to the luminosity of the object to be evaluated, ranging from black to white; $\mathrm{a}^{*}$ is a measure of chroma in the red-green axis; and $b^{*}$ is a measure of chroma in the yellow-blue axis. In this way, the CIE $\mathrm{L}^{*}$ value varies from 0 (black) to 100 (white), the CIE a* value can be positive (red) or negative (green), and the CIE $b *$ value characterizes yellowness or blueness if positive or negative, respectively. ${ }^{8}$

To examine the methodology for color selection, Analoui et al. ${ }^{9}$ studied digital photos, spectrophotometers and colorimeters, highlighting the importance of reducing color selection errors in dental practices. Among the instruments to be employed, Sarafianou et al. ${ }^{10}$ suggested the use of digital cameras, and Yuan et al. ${ }^{11}$ recommended the use of the digital Easyshade spectrophotometer.

After analyzing the optimal environment for color selection, Jun ${ }^{12}$ suggests a gray-neutral envi- ronment because this color is a component of all primary and secondary colors; as for lighting, this study suggests the use of fluorescent lamps, which represent the light of day.

When employing the photographic system for color analysis, the mode of the camera, whether manual or automatic, must be considered because the mode may influence the coordinates that make up the color.

Although the process of color selection is subjective, a pattern must be followed using a straightforward method to avoid communication errors between professionals involved in rehabilitation and prosthetic dentistry. It is possible to use a camera, transferring photos to image processing software that can evaluate each of the three coordinates numerically, allowing for the calculation of the difference in total color $(\Delta \mathrm{E})$ from the values obtained. Johnston and $\mathrm{KaO}^{13}$ proposed a threshold of visual perception in accordance with the CIE L*a*b* system, in which the $\Delta \mathrm{E}$ value would be visually imperceptible when it reached a total color difference of 3.7, which is clinically acceptable.

Considering that the most used color selection scale by dental professionals is Vita Lumin Vacuum, we sought to compare the automatic and manual modes of a digital camera using software for processing captured images and checking the difference in the color presented using the CIE L*a*b* system. Thus, the main objective of this study was to investigate two modes of taking photographs (automatic and manual), applying the CIE L*a*b* system.

\section{Methodology}

The color scale Vita Lumin Vacuum (Zahnfabrik Vita, Bad Sackingen, Germany) with 16 shades was chosen. We also selected four tabs (A3.5, B1, B3 and $\mathrm{C} 4)$, in which dark colors were represented by $\mathrm{C} 4$ and A3.5, and clear colors were represented by B1 and $\mathrm{B} 3$.

For taking the photographs, we used a Canon EOS Rebel XSi SLR (Canon, Nagasaki, Japan) camera with a telephoto EF $100 \mathrm{~mm}$ f/2.8 USM macro autofocus lens (Canon, Nagasaki, Japan). The camera was fixed on a static table. The adjustment of the camera was standardized in manual mode, specifi- 
cally, the settings for the aperture diaphragm (1/16), the exposure time (1/80") and the sensitivity (ASA/ ISO 100) were determined. Next, the photographs were taken in auto mode, considering the opening of the diaphragm (1/4), exposure time (1/60") and sensitivity (ASA/ISO 100). The source of light was a dedicated ring flash (Canon MR-14EX E-TTL Macro Ring Lite, Canon, Nagasaki, Japan).

The same operator obtained five photos for each shade guide tab. The pictures were taken in a professional photographic studio equipped to avoid any interference that could compromise the image quality for this research. An approximate distance of $32.5 \mathrm{~cm}$ was adopted between the lens and the object, and the guide was placed on a gray surface as recommended by Jun. ${ }^{12}$ Subsequently, the images were saved as JPEG images (file size of $2.5 \mathrm{MB}$ ) using Adobe Photoshop 7.0 software (Adobe Systems, San Jose, CA, USA), and they were analyzed by two examiners according to the coordinates $\mathrm{L}^{*}, \mathrm{a}^{*}$, and $\mathrm{b}^{*}$. Thus, a point on the shade guide tab, identified by the coordinates $(0.72,0.78)$ according to the metric ruler available in the program, was chosen to represent the middle third of the tooth. Two examiners obtained the coordinate values $\mathrm{L}^{*}, \mathrm{a}^{*}$ and $\mathrm{b}^{*}$ using the program's Labcolor module.

Adopting the same procedure mentioned above for each of the five images and for the different tabs (4), examiners (2) and methods (2), 80 total values were obtained for the analysis of the similarity of results produced by the manual and automatic modes.

Thus, adopting the CIE $L^{*} a^{*} b^{*}$ system, the measurements obtained by manual (man) and automatic (aut) were directly compared via the following calculations:

$$
\begin{aligned}
& \Delta \mathrm{L}^{*}=\mathrm{L}_{\text {man }}^{*}-\mathrm{L}^{*}{ }_{\text {aut }} \\
& \Delta \mathrm{a}^{*}=\mathrm{a}^{*}{ }_{\text {man }}-\mathrm{a}^{*}{ }_{\text {aut }} \\
& \Delta \mathrm{b}^{*}=\mathrm{b}_{\text {man }}^{*}-\mathrm{b}^{*}{ }_{\text {aut }}
\end{aligned}
$$

The total color difference $(\Delta \mathrm{E})^{1}$ was calculated as follows:

$$
\Delta \mathrm{E}=\left[\left(\Delta \mathrm{L}^{*}\right)^{2}+\left(\Delta \mathrm{a}^{*}\right)^{2}+\left(\Delta \mathrm{b}^{*}\right)^{2}\right]^{1 / 2}
$$

For each tab, the $\Delta \mathrm{E}$ value was obtained and classified as either clinically acceptable or clinically unacceptable according to the standard classification of Johnston and Kao, ${ }^{13}$ that is, a $\Delta \mathrm{E}$ value that reaches 3.7 is considered clinically acceptable. In cases in which the guide tab was classified as clinically unacceptable, the mean $(\mathrm{M})$ for each of the coordinates of the CIE L*a*b* system was calculated by point and with a $95 \%$ confidence interval (95\% CI).

\section{Results}

Table 1 shows the CIE L*a*b* coordinates according to shade tab, which were extracted from the two examiners' measurements of digitized images obtained by a photographic process in the automatic mode.

The $\Delta \mathrm{E}$ values of $0.89,1.28,0.75$ and 0.60 corresponded to A3.5, B1, B3 and C4, respectively. These values indicate a clinically acceptable difference, suggesting that the independent examiners behaved similarly in obtaining the coordinate values in the automatic mode.

Table 2 shows the CIE L*a*b* coordinates according to shade tab, which were extracted from the two examiners' measurements of digitized images obtained by a photographic process in the manual

Table 1 - Mean values of $L^{*}, a^{*}$ and $b^{*}$ according to shade tab and examiner ( $A$ and $B$ ) automatic mode.

\begin{tabular}{c|c|c|c|c|c|c|c|c|c}
\hline \multicolumn{9}{|c}{ Automatic mode } \\
\hline \multirow{2}{*}{ Guide } & \multicolumn{3}{|c|}{$\mathrm{L}^{*}$} & \multicolumn{3}{c|}{$\mathrm{a}^{*}$} & \multicolumn{3}{c}{$\mathrm{b}^{*}$} \\
\cline { 2 - 13 } & A & B & $\Delta \mathrm{L}^{*}$ & A & B & $\Delta \mathrm{a}^{*}$ & A & B & $\Delta \mathrm{b}^{*}$ \\
\hline A3.5 & 54.0 & 54.8 & 0.8 & 5.8 & 5.4 & 0.4 & 28.8 & 28.8 & 0.0 \\
\hline B1 & 61.4 & 61.4 & 0.0 & -0.8 & -1.6 & 0.8 & 13.8 & 14.8 & 1.0 \\
\hline B3 & 55.2 & 55.6 & 0.4 & 4.0 & 4.2 & 0.2 & 27.2 & 26.6 & 0.6 \\
\hline C4 & 44.4 & 44.0 & 0.4 & 5.8 & 6.2 & 0.4 & 25.6 & 25.8 & 0.2 \\
\hline
\end{tabular}


Table 2 - Mean values of $L^{*}, a^{*}$ and $b^{*}$ according to shade tab and examiner ( $A$ and $B$ ) manual mode.

\begin{tabular}{c|c|c|c|r|r|r|r|r|c}
\hline \multicolumn{9}{|c}{ Manual mode } \\
\hline \multirow{2}{*}{ Shade tab } & \multicolumn{3}{|c|}{$\mathrm{L}^{*}$} & \multicolumn{3}{c|}{$\mathrm{a}^{*}$} & \multicolumn{3}{c}{$\mathrm{b}^{*}$} \\
\cline { 2 - 11 } & A & B & $\Delta \mathrm{L}^{*}$ & A & B & $\Delta \mathrm{a}^{*}$ & A & B & $\Delta \mathrm{b}^{*}$ \\
\hline A3.5 & 50.6 & 50.4 & 0.2 & 6.8 & 6.8 & 0.0 & 26.6 & 26.6 & 0.0 \\
\hline B1 & 61.4 & 61.4 & 0.0 & -1.0 & -0.6 & 0.4 & 13.4 & 13.2 & 0.2 \\
\hline B3 & 53.2 & 52.6 & 0.6 & 4.4 & 3.8 & 0.6 & 27.2 & 26.2 & 1.0 \\
\hline C4 & 43.2 & 43.6 & 0.4 & 6.8 & 6.6 & 0.2 & 23.4 & 24.8 & 1.4 \\
\hline
\end{tabular}

Table 3 - Total color difference $(\Delta \mathrm{E})$ between the automatic and manual mode, according to shade tab.

\begin{tabular}{c|c}
\hline Shade tab & $\Delta \mathrm{E}$ \\
\hline A3.5 & 4.17 \\
\hline B1 & 0.44 \\
\hline B3 & 2.04 \\
\hline C4 & 2.69 \\
\hline
\end{tabular}

mode.

The $\Delta \mathrm{E}$ values of $0.20,0.45,1.31$ and 1.47 corresponded to A3.5, B1, B3 and C4, respectively. These values indicate a clinically acceptable difference between the examiners, suggesting that they behaved similarly to obtain the coordinates values independently in the manual mode.

The total color difference $(\Delta \mathrm{E})$ between both automatic and manual modes is shown in Table 3.

As shown in Table 3, only the A3.5 shade tab presented differences in color that would be unacceptable by the standards of Johnston and Kao. ${ }^{13}$ However, the B1, B3 and C4 shade tabs showed acceptable color differences, independent of the digital photography mode used (manual or automatic). The average values of the coordinates for the A3.5 shade tab are shown in Table 4.

The results in Table 4 show that the averages of $L^{*}$ for both the automatic and manual modes were significantly different $(\mathrm{p}<0.05)$, while the averages of $a^{*}$ and $b^{*}$ were similar. Thus, $L^{*}$ showed the highest average in the automatic mode, which may have led to unacceptable color differences between the automatic and manual modes.

\section{Discussion}

This research compared the two modes of taking
Table 4 - Mean (M), standard deviation (SD) and the 95\% confidence interval $(95 \% \mathrm{Cl})$ for the coordinates of the $\mathrm{CIE}$ $L^{*} a^{*} b^{*}$ system in the automatic (aut) and manual (man) modes - A3.5.

\begin{tabular}{c|c|r|r|r}
\hline Coordinate & Mode & \multicolumn{1}{c|}{$M$} & \multicolumn{1}{c|}{ SD } & \multicolumn{1}{c}{$95 \% \mathrm{Cl}$} \\
\hline \multirow{2}{*}{$L^{*}$} & aut & 54.0 & 0.71 & $53.11-54.89$ \\
\cline { 2 - 5 } & man & 50.6 & 0.89 & $49.49-51.71$ \\
\hline \multirow{2}{*}{$a^{*}$} & aut & 5.8 & 0.84 & $4.77-6.82$ \\
\cline { 2 - 5 } & man & 6.8 & 1.09 & $5.44-8.16$ \\
\hline \multirow{2}{*}{$b^{*}$} & aut & 28.8 & 1.30 & $27.19-30.38$ \\
\cline { 2 - 5 } & man & 26.6 & 1.14 & $27.38-28.02$ \\
\hline
\end{tabular}

photographs (automatic and manual), examining the color differences presented by each mode. We studied the Vita Lumin Vacuum scale, introduced in 1956 , as it is still the most widely used color scale by professional dental practices.

A single operator captured digital images automatically and manually with a Canon EOS Rebel XSi SRL camera. According to Schroop ${ }^{14}$ (2009), the color selection for digital photos is more reliable than the conventional visual method. Additionally, European dental students prefer digital tooth color determination. ${ }^{6}$

Pilot tests were conducted with standard conditions to adjust the camera properly to various specifications, including aperture diaphragm (1/16), exposure time (1/80"), sensitivity (ASA/ISO 100), resolution of the machine (12 Mpixels), and distance of the object $(32.5 \mathrm{~cm})$. A dedicated ring flash (Canon MR-14EX TTL Macro Ring Lite, USA) was used as a light source in automatic mode.

Two investigators completed the measurements, as they were previously calibrated to measure the coordinates of the CIE L*a*b* system. 
The ambient lighting was standardized throughout the study using a fluorescent lamp that simulates daylight, as recommended by the authors Jun, ${ }^{12}$ Azer et al.,$^{15}$ and Sproull. ${ }^{16}$

To obtain the coordinates of the CIE L*a*b* system, we used Adobe Photoshop 7.0 software, which is a useful photo editing program that offered the measures of the coordinates for this research.

Initially, we found that the data obtained by the two independent examiners were similar. The difference between the automatic and manual modes was clinically acceptable, indicating that the results were reliable. This fact can be explained by previous calibration between the modes, suggesting that the use of Adobe Photoshop 7.0 software contributed to this occurrence. This program can be of value in other studies, as it can easily obtain the coordinate values after setting a certain point to represent the middle third of the tooth guide. Thus, this research is reliable because the different examiners were previously calibrated to make reproducible independent measurements.

There is controversy in the literature regarding the maximum acceptable limit of the color difference $(\Delta \mathrm{E})$, which has been proposed to be $3.3^{17}$ or $3.7 .{ }^{13}$ The $\Delta \mathrm{E}$ presented by the automatic and manual modes for the B1, B3 and C4 shade tabs showed acceptable color differences (Table 3), independent of the manual or automatic modes. The A3.5 shade tab was classified as clinically unacceptable by the standards cited, which prompted a more detailed analysis of the coordinates for a better understanding of this finding. Thus, for the A3.5 shade tab, the average brightness was higher in the automatic mode than in the manual mode with values of 54.0 (53.11-54.89) and 50.6 (49.49-51.71), respectively. This result

\section{References}

1. Yap AU, Sim CP, Loh WL, Teo JH. Human-eye versus computerized color matching. Oper Dent. 1999 Nov;24(6):358-63.

2. Rodrigues TP, Loffredo LCM, Rastelli ANDS, Bagnato VS. Método visual de seleção de cor dental por cirurgiões dentistas no estado de São Paulo. Stoma. 2007 Set;84:20-3.

3. Mayekar SM. Shades of a color. Illusion or reality?. Dent Clin North Am. 2001 Jan;45(1):155-72. could explain the difference in color $(\Delta \mathrm{E}=4.17)$ that was higher than the maximum acceptable limit (3.7).

It is important to consider the consistency in color measurements between practitioners; as stated by Khashayar et al., ${ }^{18}$ the "dentist and the dental laboratory that work together are obliged to use the same device to communicate color between them."

This in vitro study aimed to evaluate four shade guide tabs according to the CIEL*a"b* system using digital images captured photographically in manual and automatic modes and processed by a specific software. We intended to work with photographic cameras available to professionals, offering the advantage of color selection. However, this study does not intend to exhaust the matter, and additional investigations concerning the optimal photography equipment for color analysis can be performed.

In their routine work, professionals adopt a different procedure, making a visual comparison between the chosen scale and tooth restorations and composite resin. In vitro studies and other research regarding the ideal working conditions and behavior of the guides should facilitate the clinical success of the color selection procedure.

\section{Conclusions}

For the Vita Lumin Vacuum, we observed agreement between examiners in their measurements of the coordinates for the A3.5, B1, B3 and C4 shade tabs. Considering the total color difference between the manual and automatic modes, the B1, B3, and C4 shade tabs presented clinically acceptable differences, and the camera can be used in any of the modes. However, this procedure is not recommended for the A3.5 shade tab, which demonstrated a clinically unacceptable difference between the two modes.

4. Hammad IA. Intrarater repeatability of shade selections with two shade guides. J Prosthet Dent. 2003 Jan;89(1):50-3.

5. Dagg H, O'Connell B, Claffey N, Byrne D, Gorman C. The influence of some different factors on the accuracy of shade selection. J Oral Rehabil. 2004 Sep;31(9):900-4.

6. Dozic A, Kharbanda AK, Kamell H, Brand HS. European dental students' opinions about visual and digital tooth colour determination systems. J Dent. 2011 Dec;39(3):23-8. 
7. Mutlu-Sagesen L, Ergun G, Ozkan Y, Bek B. Color stability of different denture teeth materials: an in vitro study. J Oral Sci. 2001 Sep;43(3):193-205.

8. Yamanel K, Caglar A, Ozcan M, Gulsah K, Bagis B. Assessment of color parameters of composite resin shade guides using digital imaging versus colorimeter. J Esthet Restor Dent. 2010;Dec;22(6):379-88.

9. Analoui M, Papkosta E, Cochran M, Matis B. Designing visually optimal shade guides. J Prosthet Dent. 2004 Oct;92(4):371-6.

10. Sarafianou A, Kamposiora P, Papavasiliou G, Goula H. Matching repeatability and interdevice agreement of 2 intraoral spectrophotometers. J Prosthet Dent. 2012 Mar;107(3):178-85.

11. Yuan JC, Brewer JD, Monaco EA Jr, Davis EL. Defining a natural tooth color space based on a 3-dimensional shade system. J Prosthet Dent. 2007 Aug;98(2):110-9.

12. Jun S. Communication is vital to produce natural looking metal ceramic crowns. J Dent Technol. 1997 Oct;14(8):15-20.
13. Johnston WM, Kao EC. Assessment of appearance match by visual observation and clinical colorimetry. J Dent Res. 1989 May;68(5):819-22.

14. Schropp L. Shade matching assisted by digital photography and computer software. J Prosthodont. 2009 Apr;18(3):23541.

15. Azer SS, Ayash GM, Johnston WM, Khalil MF, Rosenstiel SF. Effect of esthetic core shades on the final color of IPS Empress all-ceramic crowns. J Prosthet Dent. 2006 Dec;96(6):397-401.

16. Sproull RC. Color matching in dentistry. Part II. Practical applications of the organization of color.1973. J Prosthet Dent. 2001 Nov;86(5):458-64.

17. Vichi A, Ferrari M, Davidson CL. Color and opacity variation in three different resin-based composite products after water aging. Dent Mater. 2004 Jul;20(6):530-4.

18. Khashayar G, Dozic A, Kleverlaan CJ, Feilzer AJ. Data Comparison between two dental spectrophotometers. Oper Dent. 2012 Jan-Feb;37(1):12-20. 